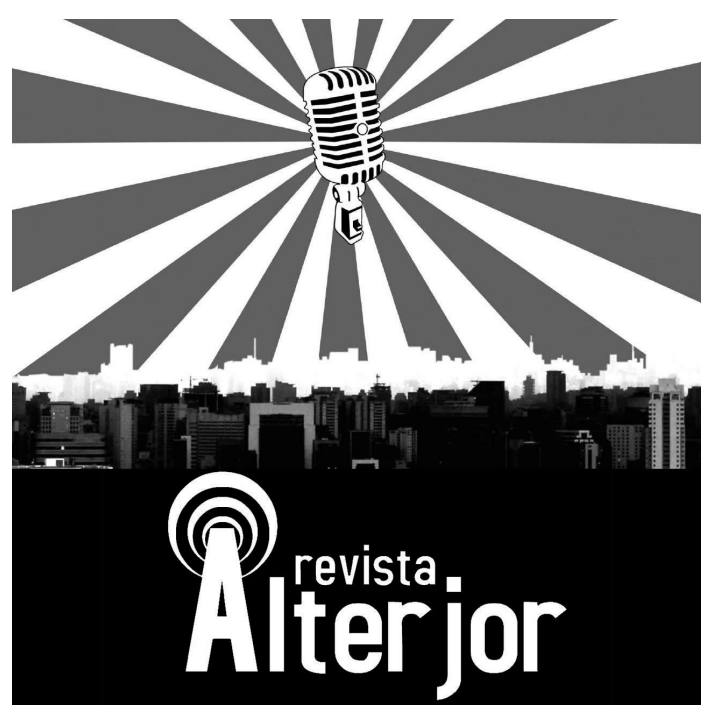

\title{
O BRANDED CONTENT COMO ESTRATÉGIA DE FINANCIAMENTO NO WEBJORNALISMO: UMA ANÁLISE DE CONTEÚDO DO ESTÚDIO FOLHA
}

\author{
Daniela Pires de Camargos Ferreira ${ }^{1}$ \\ Liana Vidigal Rocha ${ }^{2}$
}

\begin{abstract}
RESUMO: O objetivo deste artigo é analisar o branded content do Estúdio Folha, como um modelo de negócio do grupo Folha de S. Paulo. Para tanto, foi realizada a análise de conteúdo de quatro publicações digitais de diferentes anos. As categorias de análise consideradas foram: princípios jornalísticos; critérios de noticiabilidade; linguagem jornalística; técnicas de construção textual e estrutura do produto. Identificou-se que o Estúdio utiliza das ferramentas, técnicas e narrativa do jornalismo para dar visibilidade às marcas e também se apropria do espaço jornalístico para disseminar o interesse privado, além de não ser transparente sobre o redator dos conteúdos. Sugere-se que o branded content seja produzido pelas assessorias de imprensa das marcas, cabendo ao veículo apenas comercializar o espaço de divulgação e que o material venha assinado pelo jornalista ou a assessoria que o produziu.
\end{abstract}

PALAVRAS-CHAVE: Novas formas de financiamento. Webjornalismo. Modelos de negócio. Conteúdo patrocinado.

ABSTRACT: The purpose of this article is to analyze the branded content of Estúdio Folha, as a business model of the Folha de S. Paulo group. For this purpose, the content analysis of four digital publications from different years was performed. The categories of analysis considered were: journalistic principles; newsworthiness criteria; journalistic language; textual construction techniques and product structure. It was identified that the Studio uses the tools, techniques and narrative of journalism to give visibility to brands and also appropriates the journalistic space to disseminate private interest, in addition to not being transparent about the content writer. It is suggested that the branded content be produced by the press offices of the brands, with the vehicle only being responsible for marketing the advertising space and that the material be signed by the journalist or the office that produced it.

\footnotetext{
${ }^{1}$ Mestre em Comunicação e Sociedade (PPGCom) da Universidade Federal do Tocantins (UFT). E-mail: daniela.camargos@uft.edu.br.

${ }^{2}$ Docente do Programa de Pós-Graduação em Comunicação e Sociedade (PPGCom) da Universidade Federal do Tocantins (UFT).E-mail: lianavidigal@uol.com.br.
}

\section{Revista ALTERJOR}

Grupo de Estudos Alterjor: Jornalismo Popular e Alternativo (ECA-USP)

Ano 11 - Volume 02 - Edição 24 - Julho-Dezembro de 2021

Av. Professor Lúcio Martins Rodrigues, 443, Cidade Universitária, São Paulo, CEP: 05508-020 


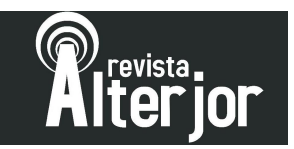

KEYWORDS: New forms of financing. Webjournalism. Business models. Branded Content.

\section{INTRODUÇÃO}

As formas de financiamento do jornalismo e os modelos de negócio adotados pelas empresas jornalísticas sempre estiveram ligadas à publicidade como maior fonte de geração de receitas. Com o surgimento e a expansão da internet, aparecem novas formas de financiamento, que vão além do modelo comercial de vendas de assinaturas de jornal impresso e dependência da tradicional publicidade. Assim, as mídias digitais trouxeram mudanças não somente no modo de se fazer jornalismo, como também transformações estruturais e econômicas. Diante dos desafios financeiros, da queda de venda dos jornais impressos, da dificuldade em atrair publicidade on-line, os veículos estão em busca de modelos de negócios que sejam capazes de unir produção de conteúdo com qualidade e viabilidade financeira.

As mutações no cenário de sustentabilidade da mídia ao redor do mundo e a crise dos modelos de negócio no jornalismo contemporâneo têm proporcionado uma busca por alternativas de monetização e modos de financiamento (LEVY; NEWMAN, 2014). Desta forma, este artigo analisa o branded content ${ }^{3}$ do Estúdio Folha, como um modelo de negócio que visa oferecer conteúdo "feito sob medida para marcas, em diferentes plataformas", utilizando, para isso, ferramentas e técnicas do jornalismo. Diferente do publieditorial, o conteúdo patrocinado possui formato informativo que privilegia o conteúdo com um foco maior no leitor.

\section{BRANDED CONTENT}

Segundo Araújo (2018), o branded content surgiu em um contexto de necessidade de as marcas almejarem visibilidade, mas sem a tradicional propaganda. "Marcas relevantes estão interessadas em contar histórias que fazem sentido para a vida das pessoas, sem incomodá-las com propaganda tradicional ou jornalismo esvaziado de conteúdo" (ARAÚJO, 2018, p. 1). Com o declínio da publicidade e as dificuldades de

\footnotetext{
${ }^{3}$ Conteúdo patrocinado
}

\section{Revista ALTERJOR}

Grupo de Estudos Alterjor: Jornalismo Popular e Alternativo (ECA-USP)

Ano 11 - Volume 02 - Edição 24 - Julho-Dezembro de 2021 Av. Professor Lúcio Martins Rodrigues, 443, Cidade Universitária, São Paulo, CEP: 05508-020 


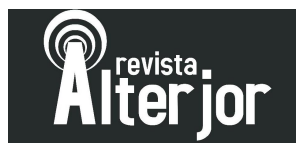

sobrevivência das empresas de comunicação no ambiente digital, houve um aumento dos estúdios de conteúdo patrocinado, como uma forma de financiamento para a mídia.

Entre os estudiosos, o branded content ainda gera divergências de visões em relação à credibilidade do material produzido. Com uma postura mais positiva em relação à iniciativa, Araújo (2018) acredita ser um "equilíbrio inteligente entre dois pilares: publicidade e jornalismo", já que há uma sinergia entre os dois campos a fim de construir sentidos, orientar, informar e entreter o consumidor.

As plataformas digitais trouxeram um aumento demasiado de conteúdo, seja noticioso, de anúncios publicitários ou até mesmo de desinformação. Desta maneira, o desafio está em construir práticas discursivas que fazem sentido e consiga a atenção do público, submerso em uma infinidade de informação. O branded content traz uma ligação intensa com o brand journalism ou também chamado de jornalismo de marca, que consiste em uma "área do jornalismo especializada em repercutir temas que estejam vinculados a marcas" (ARAÚJO, 2018, p.1).

Segundo os brand journalists Thomas Scott e Greg Lacour (2012), a cultura ocidental, durante muitos anos, foi "bombardeada" pelo marketing e a tradicional publicidade a ponto de os consumidores entenderem o jogo e não mais cederem a esse tipo de abordagem e estratégia de vendas. Dentro desse contexto, entra o jornalismo de marca, que para Scott e Lacour "é simplesmente outro tipo de jornalismo, assim como jornalismo político é jornalismo, jornalismo esportivo é jornalismo, blogs sobre questões locais são jornalismo" (SCOTT; LACOUR, 2012, tradução nossa) ${ }^{4}$. Eles contam ainda que as marcas começaram a perceber a potencialidade de histórias bem contadas, com informações e valores não produzidos pelos tradicionais anúncios publicitários.

De acordo com um artigo escrito em 2019 pelo presidente executivo da NNC (National Newsmedia Council) $)^{5}$, John Fraser, o jornalismo de marca, bem como, o conteúdo patrocinado são práticas que existem há muitos anos, mas o primordial segundo

\footnotetext{
${ }^{4}$ It's simply another kind of journalism, just as political journalism is journalism, sports journalism is journalism, blogs on local issues are journalism

${ }^{5}$ Conselho Nacional de Mídia do Canadá
}

\section{Revista ALTERJOR}

Grupo de Estudos Alterjor: Jornalismo Popular e Alternativo (ECA-USP)

Ano 11 - Volume 02 - Edição 24 - Julho-Dezembro de 2021 Av. Professor Lúcio Martins Rodrigues, 443, Cidade Universitária, São Paulo, CEP: 05508-020 


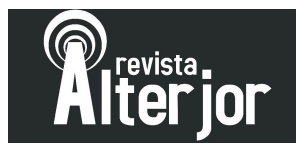

ele, consiste na forma como esse conteúdo é identificado para o público. Fraser e os membros do NNC, que defendem práticas jornalísticas éticas, afirmam que não há nada de errado com conteúdos patrocinados, desde que as publicações sejam claramente identificadas como tal e separadas dos outros conjuntos noticiosos regulares.

Um artigo publicado em julho de 2020 na Fundação Gabo ${ }^{6}$ intitulado "A fronteira entre informação e publicidade: o que os códigos éticos dizem sobre ela" (tradução nossa $^{7}$ ) traz uma compilação de códigos de ética e manuais de estilo de diversas mídias da América Latina a fim de apontar o que esses documentos declaram sobre esta divisão.

O manual do El Pitazo $^{8}$ orienta que o material deva ser produzido por uma equipe independente da redação, além de identificar para o leitor que o material se trata de conteúdo pago. O Colégio de Jornalistas da Costa Rica informa que comercialismo, concorrência desleal e enganação serão considerados atos impróprios para a prática profissional, que não pode elaborar informações tendenciosas ou enganosas, nem orientar a opinião pública com informações imprecisas e exageradas.

Já o Fórum Argentino de Jornalismo (FOPEA) aponta ser incompatível com a profissão jornalística a difusão de mensagens publicitárias explícitas ou implícitas. $\mathrm{O}$ Fórum de Jornalistas do Panamá reconhece uma incompatibilidade ética entre as profissões do jornalista, do Relações Públicas e do publicitário. O Colégio de Jornalistas do Chile orienta que "o jornalista sempre estabelecerá uma clara distinção entre mensagens informativas e publicitárias", a fim de evitar qualquer confusão ou distorção.

Observa-se entre os códigos de ética elencados acima que a recomendação mais recorrente diz respeito a uma distinção clara por parte dos veículos de comunicação entre o que é informação noticiosa e o que consiste em publicidade. As empresas de comunicação que trabalham com conteúdo patrocinado precisam ser transparentes com o

\footnotetext{
${ }^{6}$ Fundação Gabo é uma instituição de jornalismo independente criada pelo jornalista colombiano Gabriel García Márquez em 1995. Disponível em: https://fundaciongabo.org/es

${ }^{7}$ El limite entre información y publicidade: qué dicen los códigos éticos al respecto

${ }^{8}$ Uma franquia multimídia venezuelana de jornalismo independente. O termo "pitazo" relaciona-se a denúncias.
}

\section{Revista ALTERJOR}

Grupo de Estudos Alterjor: Jornalismo Popular e Alternativo (ECA-USP)

Ano 11 - Volume 02 - Edição 24 - Julho-Dezembro de 2021 Av. Professor Lúcio Martins Rodrigues, 443, Cidade Universitária, São Paulo, CEP: 05508-020 


\section{Anteier}

leitor e destacar na sua produção que o material se trata de um patrocínio por determinada marca.

\section{ESTÚDIO FOLHA}

O núcleo de conteúdo patrocinado do grupo Folha de S. Paulo, Estúdio Folha, objeto desta pesquisa, foi criado em 2015 (ver figura 01) com o objetivo de oferecer "conteúdo feito sob medida para marcas, em diferentes plataformas", utilizando para isso ferramentas do jornalismo. Essa afirmação está no ícone "quem somos" do site da iniciativa que também diz ser composta por uma equipe de jornalistas e designers gráficos responsáveis por criar e desenvolver conteúdos em formatos impresso e digital, como reportagens, vídeo, livro, revista, guias, todos aprovados pelo patrocinador.

Em uma matéria no site da Folha de S. Paulo a qual anunciava a criação do estúdio em 2015, o diretor-superintendente na época, Antonio Manuel Teixeira Mendes, afirmou que havia uma demanda alta por um tipo de comunicação além da tradicional publicidade e também que se diferenciasse dos antigos informes publicitários. "É uma tentativa de conversar com o seu cliente, com seu público, oferecendo um conteúdo que seja relevante", destacou o diretor ao enfatizar que estariam aproveitando do "DNA de produção de conteúdo" da empresa para atender às marcas. Além disso, a matéria também dizia que o novo "núcleo de negócios" era independente da redação da Folha de S. Paulo, "com o rigor e a qualidade da marca da Folha da Manhã ","

\footnotetext{
${ }^{9}$ Folha da manhã é um jornal extinto do grupo Folha que se fundiu ao jornal Folha de S. Paulo
}

\section{Revista ALTERJOR}

Grupo de Estudos Alterjor: Jornalismo Popular e Alternativo (ECA-USP)

Ano 11 - Volume 02 - Edição 24 - Julho-Dezembro de 2021 


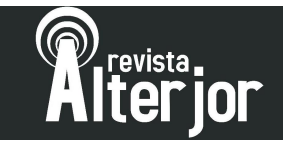

Figura 01 - Estúdio de conteúdo patrocinado do grupo Folha - Estúdio Folha

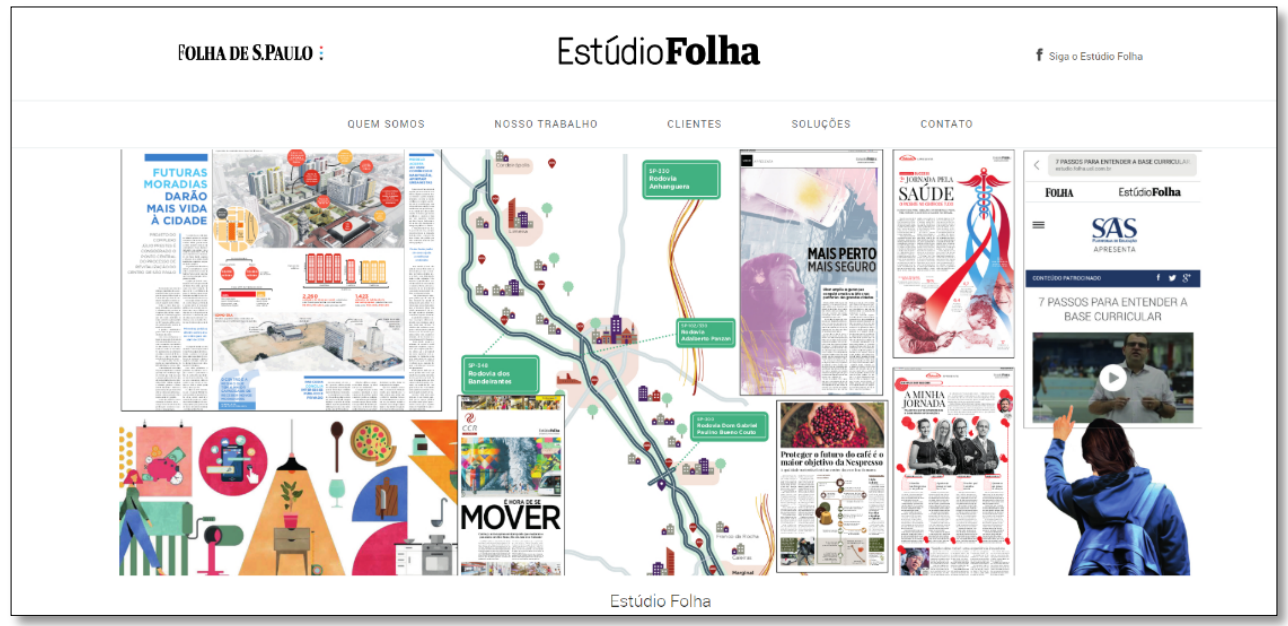

Fonte: http://estudio.folha.uol.com.br/institucional/

Ao clicar no ícone "soluções" no site do estúdio, a frase destacada "anúncios nativos de qualidade atraem mais clientes e têm se mostrado alternativa eficiente para as marcas" apresenta cinco pacotes ofertados às empresas. São eles: "Pacote impresso", "Pacote impresso + digital", "Pacote digital", "Eventos" e "Vídeos".

Nota-se que os serviços ofertados pelo Estúdio Folha vão além de conteúdo individual produzido pelo patrocínio de alguma marca ou apenas anúncio unitário, há também a possibilidade de uma equipe criar e desenvolver uma página exclusiva para o cliente, bem como, atualizá-la periodicamente como no "Pacote Digital". Desta maneira, as marcas podem contratar os serviços desses estúdios de conteúdo patrocinado como uma espécie de assessoria de comunicação, ao invés de terem jornalistas, designers gráficos ou profissionais do marketing como funcionários fixos da organização.

\section{METODOLOGIA}

O Estúdio Folha produz conteúdo para o meio impresso e digital. Foram escolhidas para esta pesquisa quatro publicações digitais, uma vez que a presente pesquisa aborda os novos modelos de negócios praticado na web. Além do critério digital, também foram selecionadas publicações de diferentes anos $(2017,2018,2019$ e 2020) a fim de construir um possível panorama com as características dos conteúdos produzidos pela iniciativa no decorrer dos anos. Ademais, também foram selecionados conteúdos

\section{Revista ALTERJOR}

Grupo de Estudos Alterjor: Jornalismo Popular e Alternativo (ECA-USP)

Ano 11 - Volume 02 - Edição 24 - Julho-Dezembro de 2021 Av. Professor Lúcio Martins Rodrigues, 443, Cidade Universitária, São Paulo, CEP: 05508-020 


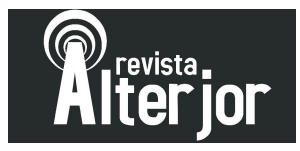

patrocinados por marcas de diferentes ramos do mercado (Nespresso, St. Marche, Unopar e Cofen).

A presente pesquisa adotou a abordagem qualitativa, uma vez que se pretende aprofundar o conhecimento em um objeto, para assim, compreender e construir uma possível realidade do conteúdo patrocinado desenvolvido no Estúdio Folha. Desta forma, "a pesquisa qualitativa não se preocupa com representatividade numérica, mas, sim, com o aprofundamento da compreensão de um grupo social, de uma organização, etc. (GERHARDT; SILVEIRA, 2009, p. 31). Para Flick (2009), a investigação qualitativa, parte da noção da construção social das realidades em estudo. Em relação à natureza, é utilizada a pesquisa básica, que segundo Gerhardt e Silveira (2009) tem como objetivo gerar conhecimentos novos sem a necessidade de aplicação prática prevista.

Após a coleta do material, foi realizada a análise de conteúdo. Foi considerada a existência ou não de elementos de uma narrativa jornalística no material produzido pelo Estúdio Folha. As categorias de análise consideradas foram: a) princípios jornalísticos (objetividade, neutralidade, imparcialidade); b) critérios de noticiabilidade; c) estrutura jornalística (técnicas de construção textual); d) estrutura do produto (elementos de mídia) e e) linguagem (jornalística e/ou publicitária).

\section{ANÁLISE DO CONTEÚDO}

A primeira publicação selecionada é do ano de 2017 e patrocinada pela marca Nespresso, intitulada "Nespresso: o futuro do café". O segundo conteúdo, de 2018, patrocinado pela rede de supermercados St. Marche tem como título "Alimentos Minelares", o de 2019, "Pós-graduação à distância", da marca Unopar, e o último de 2020, "Perigos da Covid", patrocinado pelo Conselho Federal de Enfermagem - Cofen (ver figura 02). As quatro publicações trazem a marca do Grupo Folha de S. Paulo, do Estúdio Folha, do patrocinador e uma etiqueta informando que o material se trata de conteúdo patrocinado.

\section{Revista ALTERJOR}

Grupo de Estudos Alterjor: Jornalismo Popular e Alternativo (ECA-USP)

Ano 11 - Volume 02 - Edição 24 - Julho-Dezembro de 2021 Av. Professor Lúcio Martins Rodrigues, 443, Cidade Universitária, São Paulo, CEP: 05508-020 


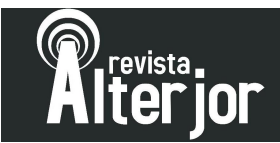

Figura 02 - Publicações analisadas

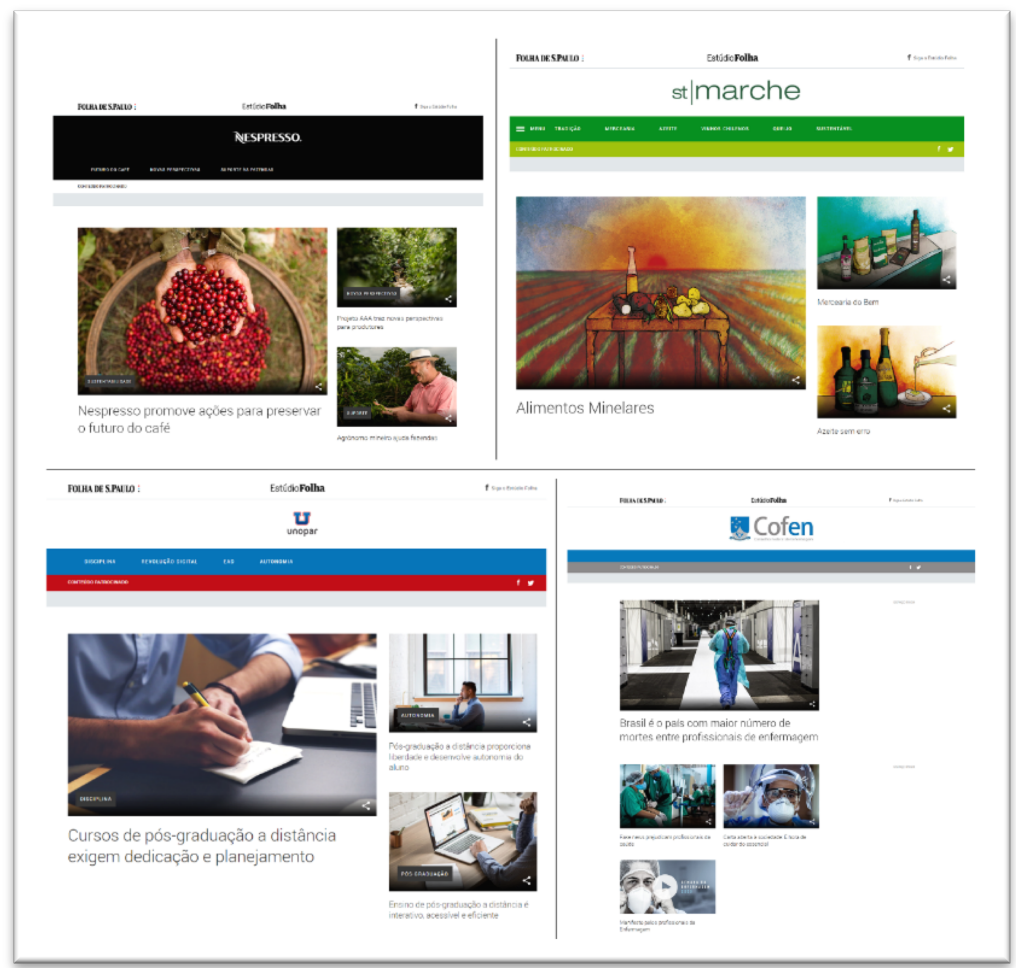

Fonte: http://estudio.folha.uol.com.br

O conteúdo acima foi objeto de análise da dissertação do mestrado acadêmico em Comunicação e Sociedade da Universidade Federal do Tocantins- UFT, que trouxe uma descrição analítica de cada matéria, antes de adentrar na análise de conteúdo de fato. Para este artigo, não foi possível trazer essa descrição detalhada que deu fruto às informações do quadro comparativo abaixo (ver quadro 01).

Quadro 01- Análise comparativa entre as publicações do Estúdio Folha

\begin{tabular}{|c|c|c|c|c|}
\hline $\begin{array}{c}\text { Categorias de } \\
\text { análise }\end{array}$ & $\begin{array}{c}\text { Publicação } \\
\text { Nespresso }\end{array}$ & $\begin{array}{c}\text { Publicação } \\
\text { St. Marche }\end{array}$ & $\begin{array}{c}\text { Publicação } \\
\text { Unopar }\end{array}$ & $\begin{array}{c}\text { Publicação } \\
\text { Cofen }\end{array}$ \\
\hline Princípios jornalísticos & $\begin{array}{c}\text { Pouca } \\
\text { apuração; } \\
\text { fontes não } \\
\text { diversificadas; }\end{array}$ & $\begin{array}{c}\text { Não traz } \\
\text { nenhuma } \\
\text { fonte; sem } \\
\text { apuração }\end{array}$ & $\begin{array}{c}\text { Traz fontes } \\
\text { diversificadas }\end{array}$ & $\begin{array}{c}\text { Fontes } \\
\text { diversificadas } \\
; \text { dados; } \\
\text { números e } \\
\text { estatísticas }\end{array}$ \\
\hline
\end{tabular}

\section{Revista ALTERJOR}

Grupo de Estudos Alterjor: Jornalismo Popular e Alternativo (ECA-USP)

Ano 11 - Volume 02 - Edição 24 - Julho-Dezembro de 2021 


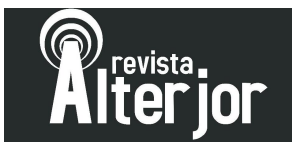

\begin{tabular}{|c|c|c|c|c|}
\hline $\begin{array}{l}\text { Critérios de } \\
\text { noticiabilidade/valores } \\
\text {-notícias }\end{array}$ & $\begin{array}{c}\text { Matéria-fria; } \\
\text { novidade; } \\
\text { utilidade; } \\
\text { proximidade; } \\
\text { impacto; } \\
\text { inovação e } \\
\text { consequência } \\
\text { s }\end{array}$ & $\begin{array}{c}\text { Matéria-fria; } \\
\text { curiosidade; } \\
\text { inovação e } \\
\text { conheciment } \\
\text { o }\end{array}$ & $\begin{array}{c}\text { Matéria-fria; } \\
\text { número de } \\
\text { pessoas } \\
\text { envolvidas; } \\
\text { atualidade; } \\
\text { utilidade; } \\
\text { oportunidade } \\
\text { e } \\
\text { conhecimento }\end{array}$ & $\begin{array}{c}\text { Matéria- } \\
\text { quente; } \\
\text { interesse } \\
\text { público; } \\
\text { atualidade; } \\
\text { utilidade; } \\
\text { impacto; } \\
\text { importância e } \\
\text { identificação } \\
\text { social e } \\
\text { humana }\end{array}$ \\
\hline $\begin{array}{l}\text { Linguagem jornalística } \\
\text { e/ou Publicitária }\end{array}$ & $\begin{array}{l}\text { Títulos na } \\
\text { ordem direta; } \\
\text { texto conciso; } \\
\text { termos mais } \\
\text { próximos da } \\
\text { linguagem } \\
\text { publicitária }\end{array}$ & $\begin{array}{c}\text { Títulos } \\
\text { inadequados; } \\
\text { texto claro, } \\
\text { porém não } \\
\text { atrativo }\end{array}$ & $\begin{array}{c}\text { Títulos na } \\
\text { ordem direta; } \\
\text { texto conciso, } \\
\text { claro e } \\
\text { objetivo }\end{array}$ & $\begin{array}{c}\text { Títulos na } \\
\text { ordem direta; } \\
\text { texto conciso, } \\
\text { claro e } \\
\text { objetivo }\end{array}$ \\
\hline $\begin{array}{ll}\text { Técnicas } & \text { de } \\
\text { construção textual } & \end{array}$ & $\begin{array}{l}\text { Linha-fina; } \\
\text { fotolegenda; } \\
\text { sem lead; } \\
\text { nariz de cera; } \\
\text { pirâmide } \\
\text { normal e falas } \\
\text { diretas com } \\
\text { aspas e } \\
\text { indiretas }\end{array}$ & $\begin{array}{l}\text { Sem linha- } \\
\text { fina; sem } \\
\text { lead e nariz } \\
\text { de cera }\end{array}$ & $\begin{array}{c}\text { Sem linha- } \\
\text { fina; nariz de } \\
\text { cera; } \\
\text { pirâmide } \\
\text { normal e falas } \\
\text { diretas com } \\
\text { aspas e } \\
\text { indiretas }\end{array}$ & $\begin{array}{l}\text { Legenda; } \\
\text { linha-fina; } \\
\text { lead e falas } \\
\text { diretas com } \\
\text { aspas e } \\
\text { indiretas }\end{array}$ \\
\hline $\begin{array}{l}\text { Estrutura do produto } \\
\text { (elementos de mídia) }\end{array}$ & $\begin{array}{l}\text { Texto, foto, } \\
\text { infográfico e } \\
\text { hiperlink }\end{array}$ & $\begin{array}{l}\text { Texto e } \\
\text { imagem }\end{array}$ & $\begin{array}{l}\text { Texto, foto, } \\
\text { hiperlink e } \\
\text { infográfico }\end{array}$ & $\begin{array}{l}\text { Texto, foto, } \\
\text { infográfico e } \\
\text { vídeo }\end{array}$ \\
\hline
\end{tabular}

Fonte: produção própria

A partir destas informações, nota-se uma característica em comum das publicações em trabalhar com um maior número de fontes ligadas diretamente à marca patrocinadora. Até mesmo nas matérias que exploraram personagens diversificados, a visibilidade maior se deu para os gestores da marca. A publicação da Nespresso trouxe três personagens, o produtor de café, Robson Vilela, o agrônomo, Newton Beraldo e o responsável pelo Programa de sustentabilidade da empresa, Guilherme Amado.

Lopes (2016) propõe um modelo taxonômico para a classificação das fontes jornalísticas baseado em seis variáveis, a) número de fontes, que diz respeito à quantidade de fontes utilizadas, se zero, uma, duas ou mais; b) composição, se é individual ou coletiva; c) identificação, se são fontes identificadas, não-identificadas ou anônimas; d) geografia, em relação ao lugar de onde se fala, nacional ou internacional; e) sexo,

\section{Revista ALTERJOR}

Grupo de Estudos Alterjor: Jornalismo Popular e Alternativo (ECA-USP)

Ano 11 - Volume 02 - Edição 24 - Julho-Dezembro de 2021 


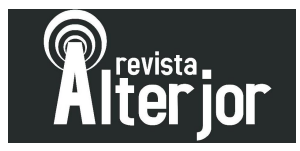

masculino, feminino ou desconhecido e f) estatuto, o qual se divide em duas categorias, fontes humanas e não-humanas, relacionadas à condição específica de quem fala

As fontes exploradas no material produzido para a Nespresso enquadram-se na macro-categoria "Humanas" e na categoria "Profissionais". Em nenhuma das três publicações da marca houve o uso de fontes independentes, aquelas sem um interesse específico ou ligação direta à empresa, denominada de "Cidadãos", na classificação de Lopes (2016). Segundo o autor, a quantidade de fontes citadas é um fator relevante, pois depreende-se se o jornalista atende ao princípio do contraditório ouvindo variadas versões dos fatos ou se relata de forma parcial o assunto.

Como o conteúdo da Nespresso explora as práticas sustentáveis da empresa, como cápsulas de café reutilizáveis, pontos de coleta, cidades em que a empresa realiza entrega e retirada das cápsulas na casa do consumidor, poderia ter sido trabalhado algum desses envolvidos como fonte. Já no conteúdo patrocinado pelo St. Marche "Alimentos Minelares" não há nenhum personagem na narrativa, que apenas apresenta os produtos do supermercado. Ou seja, infere-se que não houve apuração, entrevista, apenas um texto para dar publicidade aos itens da empresa. Para Lopes (2016), a ausência de fontes é uma característica bastante expressiva, pois revela que a matéria não está sustentada em nenhuma informação advinda de pessoas ou documentos. "Ora, como os jornalistas não podem constituir-se como fontes de si próprios, o texto em causa está amputado de uma parte essencial que lhe garanta a credibilidade necessária" (LOPES, 2016, p. 184).

A publicação da Unopar fez uso de seis fontes distintas, sendo duas enquadradas na categoria "Cidadãos", Letícia Ribeiro e Luana Pereira, ambas pós-graduadas na instituição, e quatro "Profissionais", a diretora da Associação Brasileira de Ensino a Distância - Abed, Rita Maria Lino Tarcia, a gerente de operação, produção e entrega da Kroton, um grupo de ensino privado, Alessandra Fahl, o gerente de sistemas e tecnologias de negócios também da Kroton, Volnei Munhoz e outro representante da Abed, Josiane Tonelotto. Essa diversificação de fontes traz robustez à matéria e diferentes pontos de vista, repassando assim, maior imparcialidade e cumprimento aos procedimentos de apuração do jornalismo, bem como, os dois lados dos envolvidos ao tema.

\section{Revista ALTERJOR}

Grupo de Estudos Alterjor: Jornalismo Popular e Alternativo (ECA-USP)

Ano 11 - Volume 02 - Edição 24 - Julho-Dezembro de 2021 Av. Professor Lúcio Martins Rodrigues, 443, Cidade Universitária, São Paulo, CEP: 05508-020 


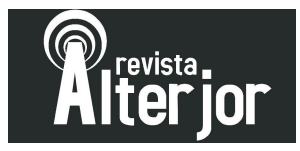

Por constituir-se em uma autarquia federal ${ }^{10}$, o Cofen trabalhou com duas fonteshumanas no texto, o presidente da instituição, Manoel Neri, o qual enquadra-se na categoria de fonte oficial, pois detêm um cargo público e a enfermeira Lurdes Gonchorowiski, fonte profissional, aquela que é remunerada por exercer determinada profissão. Apesar de trazer alguns profissionais de enfermagem em uma galeria de fotos, a primeira matéria trouxe somente a figura do presidente e suas falas diretas e indiretas. Já a segunda explorou o caso da enfermeira Lurdes, mas também com enfoque maior para o gestor do Conselho.

No conteúdo que traz à tona as dificuldades dos profissionais da enfermagem no combate à Covid-19, faltou os testemunhos dos envolvidos, mas o que se percebe é o presidente como o porta-voz das dificuldades enfrentadas pela classe. Lopes (2016) destaca que a composição da fonte pode se apresentar de forma coletiva ou individual. A primeira é quando a fonte citada se constitui no modelo de um conjunto de documentos ou pessoas, ou seja, aquele quem fala está dizendo também o que as outras pessoas envolvidas pensam ou queriam dizer. Já a composição individual é quando a fonte é apresentada de maneira singular. Nesse sentido, verifica-se esse atributo da composição coletiva na pessoa do presidente do Cofen, como aquele que fala pela categoria, uma vez que é papel do órgão disciplinar o exercício dos profissionais de enfermagem no Brasil.

Além das fontes-humanas, o material do Cofen também explorou sobremodo as fontes não-humanas, os dados do Conselho Internacional de Enfermagem (ICN), do próprio Cofen, dos conselhos regionais do Brasil, do Colégio de Enfermaria da Espanha, da Federação de Enfermagem da Itália e do Conselho de Enfermagem dos Estados Unidos. Os números de óbitos dos profissionais de enfermagem pela Covid-19, as estatísticas e comparações entre países e regiões brasileiras mostram que o material está sustentado por uma diversidade de fontes, trazendo um relato repleto de informações de interesse público, pois situa o leitor sobre as condições que o Brasil se encontra em relação à doença e repassa maior veracidade ao relato.

\footnotetext{
${ }^{10}$ Segundo a jurista Maria Sylvia Di Pietro autarquia é uma "pessoa jurídica de direito público, criada por lei, com capacidade de autoadministração, para o desempenho de serviço público descentralizado".
}

\section{Revista ALTERJOR}

Grupo de Estudos Alterjor: Jornalismo Popular e Alternativo (ECA-USP)

Ano 11 - Volume 02 - Edição 24 - Julho-Dezembro de 2021 


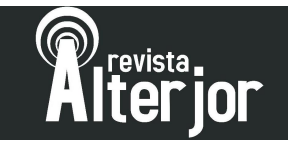

No que tange aos critérios de noticiabilidade, traquina (2002) classifica-os em dois tipos: 1) critérios de seleção, que estão relacionados aos critérios utilizados pelos jornalistas na primeira fase de escolha do acontecimento e os 2) critérios de construção, que dizem respeito à forma de apresentação da matéria, sobre o que deve ser prioridade, ser ressaltado ou excluído. O autor traz ainda os valores-notícias de cada etapa. $\mathrm{Na}$ fase de seleção: morte, notoriedade, proximidade, relevância ou impacto, novidade, atualidade, cabide noticioso ${ }^{11}$, notabilidade, surpresa, conflito ou controvérsia, infração e escândalo. Na construção do conteúdo, os valores-notícias estão no potencial de ampliar o acontecido por meio da notícia, na relevância, ou seja, na capacidade que tem a notícia de dar importância ao ocorrido, no potencial de personalizar e dramatizar a história e na consonância, como a capacidade de enquadrar o acontecimento em quadros já existentes.

McGregor (2002), Harcup e O’Neill (2016) propõe valores-notícias mais contemporâneos em relação à lista desenvolvida pelos dinamarqueses Galtung e Ruge (1965), pioneiros nos estudos sobre os critérios de noticiabilidade. Os autores adicionam os valores da: 1) visualidade; 2) emoção; 3) conflito; 4) a "celebrificação" do jornalista; 5) compartilhamento e 6) acompanhamento.

Apesar do conteúdo patrocinado ser demandado por uma marca, infere-se que o redator/jornalista selecionou juntamente com a empresa um tema para veiculação que supostamente teria um valor-notícia elevado para o público ou que trouxesse à tona valores com os quais a marca quer ser associada (ARAÚJO, 2018). Nesse sentido, percebe-se que a Nespresso deseja ser associada a práticas sustentáveis, trazendo a característica da "novidade" (o reaproveitamento das cápsulas de café e a entrega e busca em casa), da "utilidade" (informar os interessados em reaproveitar suas cápsulas ou se desfazerem das mesmas), da "proximidade" (São Paulo e Rio de Janeiro buscam em casa), do impacto (do consumo sustentável, bem como das práticas mais saudáveis ao meio ambiente), da "inovação" (prática de ir até a casa do cliente) e das "consequências" (de um consumo de café com menos poluição ambiental).

\footnotetext{
${ }^{11}$ Datas comemorativas são como um cabide noticioso, ou seja, pretextos para determinadas notícias. Por exemplo, no dia da páscoa pode ser trabalhado notícias de cunho religioso e relacionadas aos preços dos ovos de chocolate.
}

\section{Revista ALTERJOR}

Grupo de Estudos Alterjor: Jornalismo Popular e Alternativo (ECA-USP)

Ano 11 - Volume 02 - Edição 24 - Julho-Dezembro de 2021 


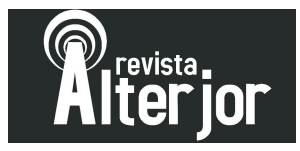

O conteúdo da rede de supermercados St. Marche possui como valores-notícia a "curiosidade" (o que é e quais alimentos são os chamados "minelares"), a "inovação" (fornecedor que eliminou a prática de queimadas e agrotóxicos, implementando um novo controle biológico de pragas) e o "conhecimento" (variados tipos de azeite e as combinações com cada tipo de comida). Já a publicação da Unopar trabalha com os atributos: "número de pessoas envolvidas" (modalidade de ensino a distância atrai cada vez mais o público), "atualidade" (a forma de estudo é uma tendência da sociedade atual), "utilidade" (entender como funciona o EAD), "oportunidade" (Canal Conecta, que permite o contato entre estudantes e empresas com oportunidades de emprego) e "conhecimento" (informar sobre os cursos ofertados, as plataformas utilizadas e o que envolve a modalidade de ensino).

Embora as empresas patrocinadoras das publicações constituam-se de diferentes ramos do mercado, alimentício, educação e saúde, observa-se uma linearidade nas publicações em trabalhar com conteúdos mais frios, atemporais e sem a menção de datas, o que torna o material 'veiculável' a qualquer momento pela marca em seus sites e redes sociais. A única publicação que trouxe um tema mais quente e atual foi o conteúdo do Cofen, que trabalhou com os "Perigos da Covid" e está volvido de valores-notícia como o do "interesse público", “atualidade”, "utilidade”, “impacto", “importância", "identificação social” e "identificação humana".

Silva (2005) enfatiza ainda que além desse primeiro filtro sobre o que será ou não veiculado, existem outras “peneiras” em relação ao que já foi selecionado, como exemplo, qual dos conteúdos será destaque na página do site ou capa do impresso ou a chamada no telejornal. Observa-se que o destaque dos conteúdos da Nespresso, St Marche, Unopar e Cofen foram, respectivamente, "Nespresso promove ações para preservar o futuro do café", “Alimentos Minelares”, "Cursos de pós-graduação a distância exigem dedicação e planejamento" e "Brasil é o país com maior número de mortes entres profissionais de enfermagem". Desta maneira, "a seleção, portanto, se estende redação adentro, quando é preciso não apenas escolher, mas hierarquizar" (SILVA, 2005, p. 98).

\section{Revista ALTERJOR}

Grupo de Estudos Alterjor: Jornalismo Popular e Alternativo (ECA-USP)

Ano 11 - Volume 02 - Edição 24 - Julho-Dezembro de 2021 Av. Professor Lúcio Martins Rodrigues, 443, Cidade Universitária, São Paulo, CEP: 05508-020 


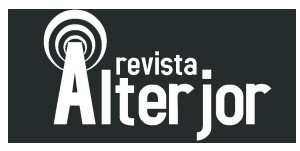

No que tange à categoria "Linguagem jornalística e/ou publicitária", Jorge (2008) elenca sete elementos do texto jornalístico, brevidade, clareza, precisão, exatidão, ritmo, simplicidade e concisão. Essas características da linguagem são encontradas nas publicações analisadas, há essa proximidade com a linguagem formal, objetiva, concisa, embora há outros elementos que não se aproximem do recomendado, como a composição dos títulos do conteúdo St. Marche: "Alimentos minelares", "Mercearia do bem" e “Azeite sem erro". Além dos títulos serem pouco chamativos, não trazem a oração completa como o recomendado, sujeito, verbo e o complemento.

No site do Estúdio Folha, a iniciativa afirma que utiliza as ferramentas do jornalismo para oferecer conteúdo para as marcas. Deste modo, as publicações, principalmente as patrocinadas pela Unopar e pelo Cofen, trazem uma consonância ao que é normatizado para a escrita do texto jornalístico, mas a essência deste, a função utilitária está mais próxima da publicidade. Na publicação da Nespresso, há termos encontrados no texto como "você", "cafezinho", que não obedecem a formalidade da narrativa do jornalismo. De acordo com Sandmann (2003), essa linguagem coloquial, informal, períodos mais curtos e o uso da terceira pessoa do singular - você, é típica da linguagem publicitária, que precisa persuadir e convencer o leitor.

Observa-se que de todas as matérias analisadas, apenas uma patrocinada pelo Cofen, "Brasil é o país com maior número de mortes entre profissionais de enfermagem", explorou em partes o lead clássico no primeiro parágrafo, respondendo às perguntas: $\mathrm{O}$ que? Quem? Como? e o Onde? As outras publicações trouxeram um parágrafo introdutório que retarda a entrada no assunto principal, o nariz de cera. Essa característica das narrativas de iniciar a matéria com informações menos relevantes e, assim, no decorrer do texto explorarem os fatos de crescente importância, aproxima-se da técnica de construção textual da pirâmide normal, segundo Erbolato (2004), trabalhada nos conteúdos da Nespresso e da Unopar.

Segundo Canavilhas (2014), a técnica de apresentação textual mais apropriada para o ambiente digital e suas potencialidades, consiste no sistema da pirâmide deitada, a qual explora a webnotícia em quatro níveis, Unidade Base, Nível de Explicação, Nível de

\section{Revista ALTERJOR}

Grupo de Estudos Alterjor: Jornalismo Popular e Alternativo (ECA-USP)

Ano 11 - Volume 02 - Edição 24 - Julho-Dezembro de 2021 Av. Professor Lúcio Martins Rodrigues, 443, Cidade Universitária, São Paulo, CEP: 05508-020 


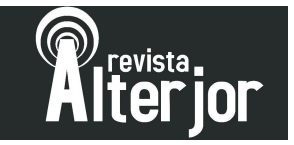

Contextualização e Nível de Exploração. Na unidade base encontra-se o primordial do lead que são as questões o quê, quando, quem e onde. No nível de explicação está a complementação da notícia com as repostas às perguntas por que e como. Já no nível de contextualização, o jornalista oferece ao leitor informações complementares, no formato de texto, vídeo, som ou imagem. Por fim, na fase nível de exploração, o texto estará ligado a outras publicações, páginas, explorando as potencialidades do hiperlink. Em nenhuma das publicações do Estúdio Folha analisadas nesta pesquisa foi trabalhado esse sistema de redação mais apropriado para o webjornalismo.

A internet como suporte da produção jornalística ampliou as possibilidades de as narrativas explorarem diversificados elementos de mídia, até então não possíveis no impresso. De acordo com Salaverría (2014), os conteúdos multimídia podem ser compostos por oito diferentes elementos: 1) texto; 2) fotografia; 3) gráficos, iconografia e ilustrações estáticas; 4) vídeo; 5) animação digital; 6) discurso oral; 7) música e efeitos sonoros e 8) vibração. Nesse sentido, verifica-se que as publicações do Estúdio Folha desenvolvidas para as marcas Nespresso, St. Marche, Unopar e Cofen trabalharam com alguns desses elementos multimídia, mas principalmente, com o texto, a fotografia e o infográfico. O hiperlink, ligando a outras páginas da web, foi melhor explorado nas matérias da Unopar que se utilizou do recurso em palavras chaves distribuídas pelo texto, não somente no final do conteúdo como a Nespresso, que apenas "linkou" o site (nespresso.com) no fim de uma única publicação.

De acordo com Colle (2004), um infográfico jornalístico precisa dos mesmos elementos de uma boa nota informativa resumida, um título que abranja a ideia central da informação e "ao mesmo tempo ser um "gancho" para criar interesse e responder a questões básicas "Quem fez o quê, onde, com que efeitos?" (COLLE, 2004, p. 11, tradução nossa $)^{12}$. Além disso, o autor pondera ser o jornalista o único capaz de apontar o que de fato merece ser "infografiado", por mais que a atribuição de fazer a peça seja do designer gráfico, não cabe apenas a ele indicar o que mostrar. $\mathrm{O}$ autor pontua ainda que

\footnotetext{
12 debe tener un título que apunte a lo medular de la información y sea a la vez un "gancho" para crear interés y debe contestar a las preguntas básicas "¿Quién hizo qué, dónde, con qué efectos?"
}

\section{Revista ALTERJOR}

Grupo de Estudos Alterjor: Jornalismo Popular e Alternativo (ECA-USP)

Ano 11 - Volume 02 - Edição 24 - Julho-Dezembro de 2021 


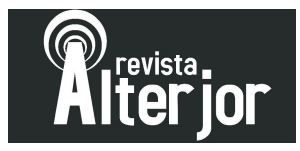

mesmo o jornalista não sendo um bom desenhista, é útil que realize um esboço do que deverá ir para o infográfico. Nesse sentido, fica em evidência a necessidade de uma comunicação integrada, a fim de desenvolver um material de qualidade.

Teixeira e Rinaldi (2008) trazem uma classificação com três tipos de infográficos jornalísticos, de primeira, segunda e terceira gerações. O primeiro caracteriza-se pela transposição, são concebidos e publicados com a mesma lógica do impresso, não trazem nenhum atributo da linguagem do webjornalismo. Os de segunda geração são trabalhados pelas autoras como uma espécie de metáfora das infografias do impresso, mas trazem o diferencial da animação, o que proporciona ao público uma certa interação (em maior ou menor grau) por meio do descobrimento de novas informações e quadros narrativos. "Por fim, as de terceira geração que seriam, portanto, as multimídias - compreendendo o termo aqui em sentido amplo - e as mais adequadas - ao menos na perspectiva de alguns autores - ao ambiente digital”. (TEIXEIRA; RINALDI; 2008, p. 9).

Nesta perspectiva de classificação, nota-se uma maior proximidade dos infográficos trabalhados nos conteúdos da Nespresso, Unopar e Cofen, aos de primeira geração, uma vez que não trazem hipertextualidade, interação e personalização de conteúdo. Os infográficos das publicações trazem uma linguagem linear, são estáticos e não há inovação em relação ao impresso. Apesar de esteticamente atrativos, os infográficos não exploraram o link, principal elemento do hipertexto que, segundo Canavilhas (2014), além de ser um dos atributos fundamentais do webjornalismo, possibilita uma narrativa "hipermultimidiática".

De acordo com Ribas (2004), os infográficos podem aparecer no ambiente digital de duas maneiras, quando se apresentam com informações complementares à notícia, ilustrando o texto ou quando o infográfico é a própria notícia, sendo pouco utilizado nesse último caso, segundo a autora. Os três infográficos do conteúdo patrocinado pela Nespresso, "Ciclo infinito do alumínio", "7 iniciativas da Nespresso no Brasil" e "Para todos" trazem informações complementares ao texto. Já os infográficos das publicações da Unopar, "Competências desenvolvidas pelo EAD" e "Tecnologia a serviço do

\section{Revista ALTERJOR}

Grupo de Estudos Alterjor: Jornalismo Popular e Alternativo (ECA-USP)

Ano 11 - Volume 02 - Edição 24 - Julho-Dezembro de 2021 Av. Professor Lúcio Martins Rodrigues, 443, Cidade Universitária, São Paulo, CEP: 05508-020 


\section{Preiejer}

aprendizado" exploraram informações muito semelhantes às do texto, alguns trechos idênticos.

Ao analisar o único infográfico "Mortes de profissionais de enfermagem no mundo" do conteúdo do Cofen, nota-se a mesma sequência de dados e informações que foram trabalhadas no texto. O primeiro parágrafo da matéria afirma que "já são 137 as mortes de técnicos, auxiliares e enfermeiros". No infográfico, essa também é a primeira informação abordada, e assim, consecutivamente, o que é explorado no texto, também consta na infografia. Canavilhas (2014) adverte que não é somente agrupar à notícia novos elementos multimídia que expressam a mesma ideia do texto, uma vez que isso causa redundância. Para ele, as informações precisam ser complementares e trazer novos dados. Paul (2010) também frisa ser um aspecto importante das narrativas digitais trabalhar com conteúdo adicional e poder proporcionar ao leitor informações novas ou ainda direcionar a diferentes materiais. A autora pontua também que caso a notícia consiga proporcionar esse "algo a mais" torna-se mais poderosa.

Salaverría (2014) indica seis critérios de composição dos elementos de mídia (texto, fotografia, gráficos, iconografia, ilustrações estáticas, vídeo, animação digital, áudio) a fim de promover a correta coordenação e composição da informação no ambiente digital. São eles: compatibilidade, complementaridade, ausência de redundância, hierarquização, ponderação e adaptação.

Deste modo, analisando o primeiro critério, o da compatibilidade, junto ao conteúdo desenvolvido para a marca Nespresso, percebe-se que o usuário não precisa de um esforço ou exigência cognitiva para assimilar a publicação, que trabalhou de forma harmoniosa e compatível com o texto, foto, infográfico e o áudio com o som da leitura do texto. Já o conteúdo da St. Marche, que trouxe os elementos do texto, ilustrações estáticas e o áudio da leitura do texto, já não houve a mesma compatibilidade, pois, os elementos seguiram uma ordem pouco atrativa para o ambiente digital, foto e bloco de texto.

A publicação da Unopar, apesar de trazer as fotos na página inicial, quando o usuário adentra no primeiro conteúdo, há apenas o elemento do texto, já na segunda e

\section{Revista ALTERJOR}

Grupo de Estudos Alterjor: Jornalismo Popular e Alternativo (ECA-USP)

Ano 11 - Volume 02 - Edição 24 - Julho-Dezembro de 2021 Av. Professor Lúcio Martins Rodrigues, 443, Cidade Universitária, São Paulo, CEP: 05508-020 


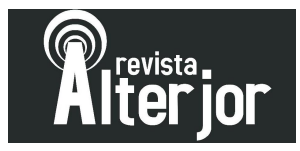

terceira matérias, trabalharam com o texto e o infográfico no fim. Pelo fato dos textos serem longos, a impressão que se dá é que o usuário talvez não chegue até o infográfico, elemento protagonista da publicação. Desta maneira, os elementos poderiam ter sido explorados de uma forma mais compatível e atrativa, sem exigir tamanho esforço do leitor, para chegar ao ponto de maior destaque das matérias.

O material do Cofen também explorou os elementos de forma mais compatível e atraente. A abertura das matérias se deu com fotos chamativas, seguido do texto, infográfico e vídeo, este último utilizado apenas na primeira publicação. Apesar do conteúdo ser extenso, a disposição dos elementos audiovisuais intercalando o texto, trouxe um conjunto de informações mais harmoniosa, compatível e interligada.

Salaverría (2014) traz o critério da complementaridade dos elementos ligados diretamente à homogeneidade temática e de extensão. Nesse sentido, nota-se que as marcas Nespresso, St. Marche, Unopar e Cofen trabalharam seus elementos multimídia com similaridade de temas. Já em relação ao tamanho, os conteúdos da Nespresso, Unopar e Cofen trouxeram muita informação no texto, no infográfico e na quantidade de fotos, ou seja, o leitor dificilmente disporá de tempo para se dedicar a essa quantidade de informações sobre um mesmo assunto.

Em relação à hierarquização dos elementos multimídia, a St. Marche dispôs de forma adequada, pois deu protagonismo à foto na entrada, elemento de maior destaque do conteúdo, seguido do texto. A Nespresso também trabalhou primeiramente com a foto, texto, infográfico e mais texto. Já as publicações da Unopar, deram mais visibilidade ao texto, sendo o elemento de maior protagonismo, o infográfico, deixado para o final. $\mathrm{O}$ redator do Cofen também trabalhou com os elementos multimídia de maneira atrativa, iniciou as três matérias com fotos de destaques, porém deixou o vídeo da primeira publicação para o final, um recurso audiovisual que poderia ter sido explorado no início ou intercalado ao texto.

Embora os conteúdos elaborados para o ambiente digital não tenham limitações de tempo e espaço, o redator precisa ponderar na quantidade de informação. Em relação a esse critério de composição, observa-se que os conteúdos analisados são extensos e cada

\section{Revista ALTERJOR}

Grupo de Estudos Alterjor: Jornalismo Popular e Alternativo (ECA-USP)

Ano 11 - Volume 02 - Edição 24 - Julho-Dezembro de 2021 Av. Professor Lúcio Martins Rodrigues, 443, Cidade Universitária, São Paulo, CEP: 05508-020 


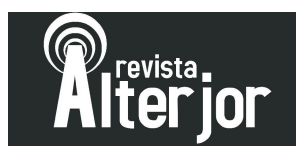

um composto por várias matérias, além de variados elementos multimídia carregados de informação. Assim o leitor precisará de tempo para consumir todo o conteúdo. Nesse segmento, um material mais conciso talvez obtivesse maior atenção do público, pois há uma diferença entre o tempo que o leitor se dedicará a uma notícia de fato jornalística, do tempo aplicado a um conteúdo patrocinado, bem como à publicidade.

\section{CONSIDERAÇÕES FINAIS}

Os estúdios de conteúdo patrocinado como um modelo de negócio e uma forma de financiamento crescentes dos veículos de comunicação colocam em evidência a necessidade de uma clara separação entre o que é notícia e o que é publicidade, pois a transparência se tornou um dos pilares primordiais do atual jornalismo. Nesse sentido, pôde-se perceber com esta pesquisa que apenas indicar nas publicações o selo de “conteúdo patrocinado", necessariamente, não é a forma mais apropriada de demonstrar transparência ao público, principalmente se esse tipo de material vier diluído com o conjunto noticioso "normal" do veículo.

Além disso, apesar do Estúdio Folha na aba "Quem somos" informar que o material é produzido por uma equipe de jornalistas e designer gráficos, os conteúdos analisados não continham nenhuma assinatura de quem os produziu. Como a iniciativa oferta diferentes tipos de pacotes às marcas interessadas, ficou perceptível a diferença de qualidade, apuração, espaço, elementos de mídia utilizados de um conteúdo para outro. Presume-se então, que o conteúdo da empresa St Marche, por exemplo, que não teve nenhuma fonte (humana e não-humana), nem mesmo elementos como o infográfico, nem fotos melhores trabalhadas, adquiriu um pacote mais econômico do Estúdio ou quem o produziu não apresentou as mesmas habilidades técnicas e de apuração no tratamento da informação.

Essa característica destoante na qualidade das matérias levantou algumas conjecturas em relação ao redator do conteúdo, que pode ter sido elaborado por profissionais freelancers ou até mesmo pelas próprias assessorias de comunicação das marcas patrocinadoras. Deste modo, sugere-se que o branded content seja produzido

\section{Revista ALTERJOR}

Grupo de Estudos Alterjor: Jornalismo Popular e Alternativo (ECA-USP)

Ano 11 - Volume 02 - Edição 24 - Julho-Dezembro de 2021 Av. Professor Lúcio Martins Rodrigues, 443, Cidade Universitária, São Paulo, CEP: 05508-020 


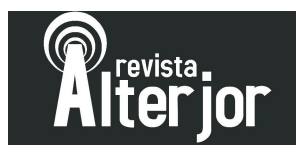

pelas assessorias, cabendo ao veículo comercializar apenas o espaço de divulgação e, nesse caso, o material venha assinado pelo jornalista que o produziu ou com a assinatura da assessoria (“Ascom”). Embora pareça algo simples, essa informação disposta ao leitor, gera maior transparência, pois ele sabe quem está por trás daquele conteúdo, além de dar visibilidade e os devidos créditos ao escritor. Com isso em mãos, o usuário pode procurar o perfil do jornalista ou da assessoria de comunicação nas redes sociais, segui-los, gerando reconhecimento e credibilidade maiores.

Essa simbiose entre jornalismo e publicidade, que Marshall (2001) identifica como jornalismo transgênico, dissolve no espaço jornalístico a natureza persuasiva da publicidade. Para o autor, a prática dissemina o interesse privado em um espaço de interesse público (imprensa) e legitima a lógica publicitária, afetando até mesmo a mentalidade dos produtores da informação. Nessa perspectiva, a notícia passa a defender o interesse privado em detrimento do interesse público e deixa de cumprir com sua função social e oferece persuasão.

\section{REFERÊNCIAS}

ARAÚJO, M. M. Brand Journalism e Branded Content: diálogos (im)possíveis no jornalismo de marca. In: Congresso anual em ciência da comunicação. Anais... Joinville - SC, 2018. Disponível em:

https://portalintercom.org.br/anais/nacional2018/resumos/R13-0884-1.pdf > . Acesso em: 22 out. 2020.

CANAVILHAS, João (Org.). Webjornalismo: 7 características que marcam a diferença. ISBN 978-989-654-144-6 (pdf). Covilhã: Livros Labcom. 2014.

CANAVILHAS, João. Webjornalismo: Da pirâmide invertida à pirâmide deitada. Disponível em: http://www.bocc.ubi.pt/pag/canavilhas-joao-webjornalismo-piramideinvertida.pdf. Acesso em: 08 de outubro de 2019.

CANAVILHAS, João. WebJornalismo: Considerações Gerais Sobre Jornalismo na Web. Portugal, Universidade da Beira Interior, 1999. Apresentação no I Congresso Ibérico de Comunicação.

CANAVILHAS, João. Hipertextualidade: novas arquiteturas noticiosas. In:

CANAVILHAS, João (orgs). Webjornalismo: 7 caraterísticas que marcam a diferença. Covilhã: UBI, livros LabCom, 2014. p. 3-24.

\section{Revista ALTERJOR}

Grupo de Estudos Alterjor: Jornalismo Popular e Alternativo (ECA-USP)

Ano 11 - Volume 02 - Edição 24 - Julho-Dezembro de 2021 Av. Professor Lúcio Martins Rodrigues, 443, Cidade Universitária, São Paulo, CEP: 05508-020 


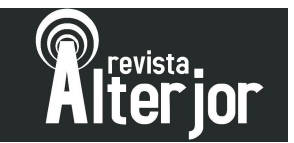

COLLE, Raymond. Infografía: tipologías. In: Revista Latina de Comunicación Social. Número 57, de enero-junio de 2004, La Laguna (Tenerife). Disponível em: http://www.ull.es/publicaciones/latina/colle2004/20040557colle.htm. Acesso em: 22 out. de 2020 .

CORREIA, Fernando. Os jornalistas e as notícias. Lisboa: Caminho, 1997, c. III, p.10521.

ERBOLATO, Mário. Técnicas de codificação em jornalismo: redação, captação e edição no jornal diário. São Paulo: Ática, 2004.

El limite entre información y publicidade: qué dicen los códigos éticos al respecto. Fundacion Gabo. 2020. Disponível em: <https://fundaciongabo.org/es/eticaperiodistica/recursos/el-limite-entre-informacion-y-publicidad-que-dicen-los-codigoseticos-al>. Acesso em: 10 set. 2020.

FLICK, U. Desenho da pesquisa qualitativa. Porto Alegre; Artmed; 2009.

FRASER, John. New frontiers in journalism ethics? Exploring "branded content". 2019. Disponível em: < https://medium.com/@CanMediaCouncil/new-frontiers-injournalism-ethics-exploring-branded-content-e692eef5ae36>. Acesso em: 28 out. 2020.

Folha cria núcleo de conteúdo patrocinado. Folha de S. Paulo. 2015. Disponível em: https://m.folha.uol.com.br/mercado/2015/10/1691039-folha-cria-nucleo-de-conteudopatrocinado.shtml. Acesso em: 05, set 2020.

GERHARDT, Tatiana Engel; SILVEIRA, Denise Tolfo (Org.). Métodos de pesquisa. Porto Alegre: Editora da UFRGS, 2009.

HARCUP, Tony, O’NEILL, Deirdre. What Is News? News Values Revisited (Again). Journalism Studies. Published electronically March 1. 2016. Disponível em: https://doi.org/10.1080/1461670X.2016.1150193. Acesso em: 28 out. 2020.

JORGE, Thais de Mendonça. Manual do Foca. Guia de sobrevivência para jornalistas. São Paulo: Contexto, 2008.

LOPES, F. Uma proposta de um modelo taxonómico para a classificação de fontes de informação. Observatorio Journal, 10 (4), 180-191. 2016. Disponível em: https://doi.org/10.15847/obsOBS1042016951. Acesso em: 29 out. 2020

LEVY, D. A. L.; NEWMAN, N. Reuters Institute News Report 2014. University of Oxford: Oxford, 2014.

MARSHALL, Leandro. Jornalismo Transgênico. INTERCOM - Sociedade Brasileira de Estudos Interdisciplinares da Comunicação - XXIV Congresso Brasileiro de Ciências da Comunicação - Campo Grande - MS. 2001.

MARSHALL, Leandro. O jornalismo na era da publicidade. São Paulo: Summus, 2003.

MCGREGOR, J. Restating news values: contemporary criteria for selecting news. 2002. Disponível em: <

\section{Revista ALTERJOR}

Grupo de Estudos Alterjor: Jornalismo Popular e Alternativo (ECA-USP)

Ano 11 - Volume 02 - Edição 24 - Julho-Dezembro de 2021 Av. Professor Lúcio Martins Rodrigues, 443, Cidade Universitária, São Paulo, CEP: 05508-020 


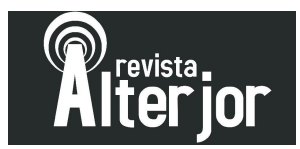

https://www.researchgate.net/publication/228774915_Restating_news_values_Contemp orary_criteria_for_selecting_the_news $>$. Acesso em: 05 nov. 2020.

PAUL, Nora. Elementos das narrativas digitais. In: FERRARI, Pollyana. Hipertexto e hipermídia. As novas ferramentas da comunicação digital. São Paulo: Contexto, 2010.

RIBAS, B. Infografia Multimídia: um modelo narrativo para o webjornalismo. In: V Congreso Iberoamericano de Periodismo en Internet, Salvador, 2004. Disponível em: http://www.facom.ufba.br/jol/pdf/2004_ribas_infografia_multimidia.pdf. Acesso em: 22 out. 2020.

SANDMANN, A. J. A linguagem da propaganda. 7. ed. São Paulo: Contexto, 2003.

SOUSA, J. P. Elementos do jornalismo impresso. Porto: Universidade Fernando Pessoa. 2001.

TEIXEIRA, T. G.; RINALDI, Mayara. Promessas para o futuro: as características do infográfico no ciberjornalismo a partir de um estudo exploratório. In: 6o. Encontro Nacional de Pesquisadores em Jornalismo, 2008, S.Bernardo do Campo. Anais do 6o. Encontro Nacional de Pesquisadores em Jornalismo. Brasília: SBPJor, 2008.

TRAQUINA, Nelson. O que é Jornalismo. Lisboa: Quimera Editores. 2002. 